\title{
One Rank Cuckoo Search Algorithm for Bi-Objective Load Dispatch Problem
}

\author{
Cuong Dinh Tran ${ }^{1 *}$, Thang Trung Nguyen ${ }^{1}$, \\ Hanh Minh Hoang ${ }^{2}$ and Bao Quoc Nguyen ${ }^{1}$ \\ ${ }^{1}$ Faculty of Electrical and Electronics Engineering, Ton Duc Thang University, \\ No. 19 Nguyen Huu Tho Street, Tan Phong Ward, Dist. 7, \\ Ho Chi Minh City, Vietnam \\ ${ }^{2}$ Faculty of Automation, Thu Duc Technology College \\ No. 53, Vo Van Ngan street, Linh Chieu ward, Thu Duc dist., \\ Ho Chi Minh City, Vietnam \\ trandinhcuong@tdt.edu.vn,nguyentrungthang@tdt.edu.vn, \\ hanh.pvmsg@gmail.com,nguyenquocbao@tdt.edu.vn
}

\begin{abstract}
This paper presents the application of a One Rank Cuckoo Search Algorithm (ORCSA) to bi-objective load dispatch (BOLD) problem where two objectives including fuel and emission are taken into consideration. ORCSA is an improvement of basic Cuckoo search algorithm (BCSA) where several modifications are carried out so as to improve the performance of the BCSA. The performance of the proposed ORCSA is validated by using two systems including a three-unit system with one load case and a six-unit system with three load cases and comparing the obtained results with other methods available in the article. The analysis on the result comparison indicates that the ORCSA is very efficient for the problem.
\end{abstract}

Keywords: One Rank Cuckoo Search algorithm, bi-objective, load dispatch, fuel cost, emission.

\section{Nomenclature}

$\begin{array}{ll}F_{l i} & \text { Fuel Cost function of thermal unit } i \text { in } \$ / \mathrm{h} \\ F_{2 i} & \text { Emission function of thermal unit } i \text { in } \mathrm{kg} / \mathrm{h} \\ w_{1,}, w_{2} & \text { Weights corresponding to the fuel cost and emission objectives. } \\ a_{i}, b_{i}, c_{i} & \text { Cost coefficients of thermal unit } i \\ d_{i}, e_{i}, f_{i} & \text { Emission coefficients of thermal unit } i \\ N & \text { Number of thermal units } \\ P_{D} & \text { Load demand of the system in MW } \\ P_{L} & \text { Total network loss of the system in MW } \\ P_{i} & \text { Power output of unit } i \text { in MW } \\ B_{i j}, B_{0 i}, B_{00} & \text { Transmission loss formula coefficients } \\ P_{\text {imin }}, P_{\text {imax }} & \text { Lower and upper generation limits of unit } i \text { in MW } \\ r a n d & \text { Uniformly distributed random number in [0, 1] } \\ P_{l d} & \text { Power output of the slack thermal unit } 1 \text { of nest } d \text { in MW } \\ P_{l \text { max }}, P_{l \min } & \text { Maximum and minimum power outputs of slack thermal unit } 1 \text { in MW } \\ P_{s}^{\lim } & \text { Limit for the slack unit } 1 \text { in MW } \\ F_{j} & \text { Value of objective } j \\ F_{j \max }, F_{j \min } & \text { Maximum and minimum values of objective } j . \\ \mu_{D}^{k} & \text { Cardinal priority of } k \text { th non-dominated solution }\end{array}$




$\begin{array}{ll}\mu\left(F^{k}{ }_{i}\right) & \text { Membership function of objective } j \\ N_{o b j} & \text { Number of objective functions } \\ N_{S} & \text { Number of Pareto-optimal solutions. } \\ \mu^{k}{ }_{D} & \text { Membership function }\end{array}$

\section{Introduction}

Bi-objective load dispatch is a very important problem in power system since both electricity generation fuel cost and emission produced from the electricity generation process are minimized in addition to satisfying all thermal unit constraints such as maximum and minimum limits on power output.

Recent decades, many methods, which based on deterministic algorithms and meta-heuristic algorithms, have been widely and successfully applied for solving the BOLD probelm such as lambda-iteration method [1], Hopfield Lagrange Network (HNN) [1], Improved Hopfield Neural Network Model (IHNN) [2], Tabu Search (TS) [3], fuzzy logic controlled genetic algorithm (FCGA) [4], the Non-dominated Sorting Genetic Algorithm - II (NSGA-II) [5], Differential Evolution (DE) [6], biogeography-based optimization (BBO) [7], multi-objective differential evolution (MODE) [8], Hybrid Differential volution-sequential quadratic programming (DESQP) and Hybrid Particle Swarm optimization- sequential quadratic programming (PSO-SQP) [9], parallel synchronous PSO algorithm (PSPSO) [10], Basic Cuckoo Search Algorithm (BCSA) [11].

Among the methods, Lamda-iteration and HNN are ones based on the Lagrange optimization function where the comer is mainly dependent on the initial value of lamda that is predetermined and the increased value of lamda whereas the later must suffer difficulty of determining control parameters. It is stated from the study [1] that the application of the methods is easy due to the simple implementation for the problem. The IHNN copes with the local optimization with high number of iteration for convergence and long execution time. The mentioned methods have the same characteristic that they can not deal with the problem where nonconvex objective function is considered. On the contrary, methods belonging to meta-heuristic algorithms such as DE, MODE, PSPSO and CSA, etc. can tackle the drawback since they simply obtain optimal solution for large scale system with nonconvex objective function. The difference between DE and MODE is that MODE can determine the best compromise solution, which can satisfy both cost and emission minimization requirement without using fuzzy mechanism like DE. The advantage allows MODE to reduce the computing procedure and execution time as well.

Recent years, the methods formed by combining two original algorithms have widely been developed for solving BOLD problem such as DE-SQP and PSO-SQP. The advantage of the methods is that they can take advantage of each individual to enhance the solution approaching the global optimization; however, the methods have to cope with the selection of higher number of control parameters and longer execution time.

In this paper, a One Rank Cuckoo Search Algorithm (ORCSA), developed by Ahmed in 2013, is proposed for solving the bi-objective load dispatch problem where two objectives including fuel and emission, and limits on power output are taken into consideration. The performance of the ORCSA has been validated by testing on different systems and compared to other methods consisting of Tabu Search (TS) [3], FCGA [4] and CGA [4], [NSGA-II [5], BBO [7], and CSA [11]. 


\section{Problem Formulation.}

The objective of the BOLD problem is to minimize both fuel cost and emission as expressed in eq. (1) below.

$\operatorname{Min} \sum_{i=1}^{N}\left(w_{1} F_{1 i}\left(P_{i}\right)+w_{2} F_{2 i}\left(P_{i}\right)\right)$

Where $F_{1 i}$ and $F_{2 i}$ are respectively the fuel cost function and emission function of thermal unit $i$. The emission is approximately represented as a quadratic function and the fuel cost is also depicted as a second order equation due to neglecting valvepoint loading effects. The two functions are shown in detail as the following equations.

$F_{1 i}=c_{i} P_{i}^{2}+b_{i} P_{i}+a_{i}$

$F_{2 i}=f_{i} P_{i}^{2}+e_{i} P_{i}+d_{i}$

On the other hands, all variables in eq. (1) must satisfy all the equality and inequality constraints below.

1. Real Power balance constraints: the total power generated by all thermal units must be equal to the sum of load demand and transmission losses.

$\sum_{i=1}^{N} P_{i}-P_{L}-P_{D}=0$

Where the transmission line power losses $P_{L}$ is determined by:

$P_{L}=\sum_{i=1}^{N_{1}} \sum_{j=1}^{N_{1}} P_{i} B_{i j} P_{j}+\sum_{i=1}^{N} B_{0 i} P_{i}+B_{00}$

2. Generator operating limits: power output of thermal unit must be in feasible operating zone.

$P_{i \text { min }} \leq P_{i} \leq P_{i \max }$

3. Weight constraint [13]: the sum of weight factors associated to fuel cost function and emission function is equal to one.

$w_{1}+w_{2}=1$

Note that the value of the weight factors decides if the economic dispatch, emission dispatch or bi-objective load dispatch are carried out. The economic dispatch is performed since the $w_{1}$ and $w_{2}$ are set to 1 and 0 whereas the emission dispatch is carried out once the $w_{1}$ and $w_{2}$ are set to 0 and 1 . For bi-objective load dispatch, a set of non-dominated solutions is determined by set $w_{1}$ and $w_{2}$ to the range from 0 to 1 so that their sum is exactly equal to one. A fuzzy mechanism is then applied to determine the best compromise solution, which is the optimal solution for the bi-objective load dispatch.

\section{One Rank Cuckoo Search Algorithm for BOLD Problem.}

\subsection{One Rank Cuckoo Search Algorithm}

In BCSA method [11], new eggs are generated two times including via Lévy Flights and via the replacement of a fraction of eggs. The new eggs obtained by the comer are 
evaluated before being replaced in the later and the eggs in the later are evaluated and ranked. In the ORCSA, the first new solutions via Lévy flights are replaced and finally evaluated and ranked at once. This manner allows ORCSA to reduce the step of fitness evaluation by combining new eggs from via Lévy Flights and via the replacement of a fraction of eggs together before evaluating their fitness function.

One more parameter introduced in ORCSA is to decide if the computational process merges the two new solution generations together, called one rank ratio $r_{o r}$. At the beginning, it is set to 1 to allow combing all new eggs from the first and second generation. This ratio is still fixed at 1 until there is no a better egg found out at the current iteration. For this case, the ratio value is set to lower value by the following rule.

$r_{o r}^{G+1}=r_{o r}^{G}-0.5 / N$

Where $G$ is the current iteration and $N$ is the number of thermal units.

\subsection{Implementation of One rank Cuckoo Search Algorithm for BOLD Problem}

The main steps for the proposed ORCSA for solving BOLD problem are described as follows:

1) Initialization: Similar to BCSA, in the ORCSA each cuckoo nest in the all initial nests $\mathrm{Np}$ is represented by a vector $X_{d}=\left[P_{d 2}, \ldots \ldots, P_{d N}\right]\left(d=1, \ldots, N_{p}\right)$. The maximum

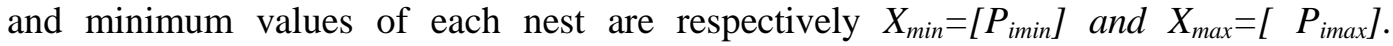
Consequently, each nest $X_{d}$ is randomly initialized within the limits $X_{\min } \leq X_{d} \leq X_{\max }(i=2$, ..., N) as follows.

$X_{d}=X_{d \text { min }}+\operatorname{rand}^{*}\left(X_{d \max }-X_{d \text { min }}\right)$

The power output of from thermal unit 2 to thermal unit $N$ is available in each nest, the thermal unit $1 P_{d l}$ for each nest $d$ is then obtained by using the eq. (4) and (5).

$P_{1 d}=\sum_{i=2}^{N} P_{i d}-P_{L}-P_{D}$

Fitness function is calculated to evaluate the quality of each solution. The value includes objective function value and the penalty value of the slack thermal unit 1 . The detail of fitness function is as below.

$F T_{d}=\sum_{i=1}^{N}\left(w_{1} F_{1 i}\left(P_{i d}\right)+w_{2} F_{2 i}\left(P_{i d}\right)\right)+K_{s}\left(P_{1 d}-P_{1 d}^{\mathrm{lim}}\right)^{2}$

Where the limit in (11) is obtained by:

$P_{1}^{\mathrm{lim}}=\left\{\begin{array}{cc}P_{1 \max } & \text { if } P_{1 d}>P_{1 \max } \\ P_{1 \min } & \text { if } P_{1 d}<P_{1 \min } \\ P_{1 d} & \text { otherwise }\end{array}\right.$

The initial population of the host nests is set to best value of each nest $X_{b e s t}$ ( $d=1$, $\left.\ldots, N_{d}\right)$ and the nest corresponding to the best fitness function in (11) is set to the best nest Gbest among all nests in the population.

\section{2) The first new solution generation via Lévy flights}

In this section, the first new solution is carried out by using Lévy flights by Mantegna's algorithm. The new solution by each nest is calculated as follows:

$X_{d}^{\text {new }}=$ Xbest $_{d}+\alpha \times$ rand $\times \Delta X_{d}^{\text {new }}$

where $\alpha>0$ is the updated step size and the increased value $\Delta X_{d}^{\text {new }}$ is determined as 
described in [11] .

\section{3) Bound by best solution for handling violated solutions}

All new solutions obtained by Lévy flights must be a feasible satisfing not only power balance constraint (4) but also minimum and maximum limits (6). Normally, as a solution violates their limits, the normal method is to set it to the maximum value in case of the maximum value violated or to minimum value if the solution is lower than minimum limit. However, a bound by best solution mechanism is first introduced in ORCSA to deal with the violation of the limits. A thermal unit in a nest is either replaced with a corresponding valid one from a randomly selected nest or randomly reinitialized in range of minimum and maximum limits. To decide the way for handling the violation, a bound by best ratio $r_{b b b}$ is defined as follows:

$r_{b b b}=1-1 / \sqrt{D}$

If $P_{i, d}$ from nest $d$ is out of its limits, a random number $r d$ is randomly generated in range $[0,1]$ and the task for dealing with issue is as below.

- Case 1: $P_{i, d}$ is initialized randomly as eq. (8) if random number $r d$ is less than $r_{b b b}$.

- Case 2: $P_{i, d}$ is replaced with $P_{i, r}$ from nest $X_{r}\left(X_{r}\right.$ is a randomly chosen nest where $P_{i, r}$ is a feasible value) if the random number $r d$ is equal to or higher than $r_{b b b}$.

4) The second new solution generation via the discovery of alien egg:

In the section, only a fraction of current solutions above is newly generated using the probability $\mathrm{Pa}$ as the following equation.

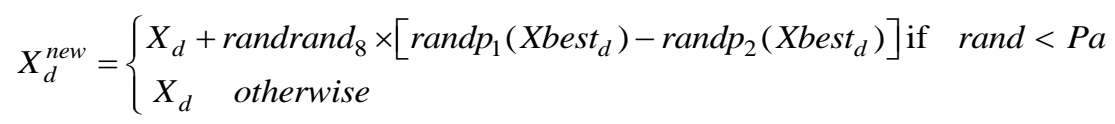

\subsection{Overall Iterative Algorithm}

The overall procedure of the proposed ORCSA for solving the BOLD problem is described as follows.

Step 1: $\quad$ Select values for control parameters $N_{p}, G_{m a x}$ and $\mathrm{P}_{a}$.

Step 2: $\quad$ Initialize a population of host nests as in eq. (9) and calculate the slack unit using eq. (10).

Step 3: $\quad$ Calculate fitness function (11) to set all nests to Xbest and the best nest with the lowest value of fitness function to Gbest. Set one rank ratio $r_{o r}=1$ and the iteration counter $G=1$.

Step 4: $\quad$ Generate new solutions via Lévy flights as in Section 3.2.2.

Step 5: Generate a random number $r d$ and compare to the one rank ratio $r_{o r}$. If the random number is higher than $r_{o r}$, go to Step 9.

Step 6: $\quad$ Generate new solution via discovery of alien eggs as in Section 3.2.4.

Step 7: $\quad$ Use bound by best solution mechanism to fix invalid solutions as in Section 3.2.3

Step 8: $\quad$ Calculate slack unit 1 and the fitness function, then rank and keep the current best nest. Go to Step 14 .

Step 9: $\quad$ Perform bound by best solution mechanism to determine a new solution.

Step 10: Calculate slack unit 1 and the fitness function, then rank and keep the current best nest.

Step 11: Discover alien eggs and randomize to generate a new solution.

Step 12: Use bound by best solution mechanism to fix invalid solutions as in Section 3.2 .3 
Step 13: Calculate slack unit 1, obtain fitness function, then rank and keep the current best nest.

Step 14: $\quad$ Store the best nest Gbest for the current iteration.

Step 15: If the current best nest Gbest is not better than that of the previous iteration, obtain the new value of the one rank ratio using (8). Otherwise, retain the old value.

Step 16: If the current iteration $G<G_{\max }, G=G+1$ and return to Step 4. Otherwise, stop the procedure.

\section{Best Compromise Solution by Fuzzy-Based Mechanism}

In the economic emission load dispatch, there is a difficulty to determine a solution which has acceptable fuel cost and emission values. In fact, as an optimal was solution found out it can certainly satisfy a particular objective due to it simple fitness function. Therefore, there is a set of non-dominated solutions are first found and then the compromise one is determined based on fuzzy satisfying method [14]. The linear membership function of the technique is as follows [14]:

$$
\mu\left(F_{j}\right)=\left\{\begin{array}{lll}
1 & \text { if } & F_{j} \leq F_{j \min } \\
\frac{F_{j \max }-F_{j}}{F_{j \max }-F_{j \min }} & \text { if } & F_{j \min }<F_{j}<F_{j \max } \\
0 & \text { if } & F_{j} \geq F_{j \max }
\end{array}\right.
$$

For each $k$ non-dominated solution, the membership function is normalized as follows [13]:

$$
\mu_{D}^{k}=\sum_{i=1}^{N o b j} \mu\left(F_{i}^{k}\right) / \sum_{k=1}^{N p} \sum_{i=1}^{N o b j} \mu\left(F_{i}^{k}\right)
$$

The solution that obtains the maximum membership $\mu_{D}^{k}$ in the fuzzy set is chosen as the 'best' solution based on cardinal priority ranking:

$\operatorname{Max}\left\{\mu_{D}^{k}: k=1,2, \ldots, N_{S}\right\}$

\section{Results and Discussions}

To validate the efficiency if the proposed ORCSA, two systems where the first one is comprised of three thermal units with transmission line power losses [5] and the second consists of six units with three load cases ranging from $800 \mathrm{MW}$ and $1200 \mathrm{MW}$ to $1800 \mathrm{MW}$ are considered [4-5]. The proposed ORCSA is coded in Matlab 7.2 programming language and run on a $1.8 \mathrm{GHz}$ PC with $4 \mathrm{~GB}$ of Ram. The ORCSA is run twenty independent trials for each case of a set control parameter.

\subsection{System I with Three Thermal Units}

For the system, three dispatch cases including economic dispatch, emission dispatch and bi-objective load dispatch are carried out to determine optimal solution. As described in 2, the optimal solution for economic dispatch is obtained as setting $w_{1}=1$ and $w_{2}=0$ and if setting $w_{1}=0$ and $w_{2}=1$, optimal solution for the emission dispatch is found out. On the other hand, the optimal solution for the biobjective load dispatch is more complicated to determine since a set non-dominated solutions is first determined and then the fuzzy technique in section 4 is applied to found out the solution. For the three cases, the number of nests and maximum number of iterations are respectively set to 12 and 45 whereas the probability $\mathrm{Pa}$ is 
set to range from 0.1 to 0.9 with a step of 0.1 for the first two dispatch cases and then the best value of probability is fixed to determine the non-dominated solutions.

As a result, the obtained results in terms of minimum cost, average cost, maximum cost, standard deviation cost and average execution time for the economic and emission dispatch are respectively indicated in Tables 1 and 2. Obviously, the best minimum cost and emission are obtained at all values of $\mathrm{Pa}$; however, the standard deviation gives a massage that the best $\mathrm{Pa}$ for economic dispatch is 0.9 and that for emission dispatch is in range from 0.1 to 0.9 . Therefore, the best value of $\mathrm{Pa}$ determined is 0.9 and it is used for searching the set of non-dominated solutions. Table 3 shows the non-dominated solutions and their membership function value. Note that the solution with the highest value of membership function value is the optimal solution for bi-objective load dispatch. As observed from the table, solution 13 is the optimal solution.

The comparison of result obtained by ORCSA and other methods including Tabu Search (TS) [3], FCGA [4] and CGA [4], [NSGA-II [5], BBO [7], and CSA [11] are reported in Table 4. Clearly, the ORCSA obtains approximate or better solution than other methods because it obtains the equal or less fuel cost and emission. In addition, the ORCSA is than CSA. Other methods have not reported their execution time. Figures 1, 2 and 3 show the fitness convergence characteristic for the three cases meanwhile the Figure 4 depicts the Pareto-solution front for fuel cost and emission. Optimal solutions for the system are indicated in Table 5.

Table 1. Obtained Results for Economic Load Dispatch for System 1

\begin{tabular}{|c|c|c|c|c|c|}
\hline$p_{a}$ & $\begin{array}{c}\text { Min. cost } \\
(\$ / \mathrm{h})\end{array}$ & $\begin{array}{c}\text { Average cost } \\
(\$ / \mathrm{h})\end{array}$ & $\begin{array}{c}\text { Max. } \\
\text { cost }(\$ / \mathrm{h})\end{array}$ & $\begin{array}{c}\text { Std. dev. } \\
(\$ / \mathrm{h})\end{array}$ & CPU time (s) \\
\hline 0.1 & 8344.5927 & 8344.6099 & 8344.8341 & 0.0546 & 0.0228 \\
\hline 0.2 & 8344.5927 & 8344.6006 & 8344.6607 & 0.0151 & 0.0222 \\
\hline 0.3 & 8344.5927 & 8344.5939 & 8344.6022 & 0.0023 & 0.0245 \\
\hline 0.4 & 8344.5927 & 8344.5935 & 8344.5993 & 0.0016 & 0.0228 \\
\hline 0.5 & 8344.5927 & 8344.593 & 8344.5945 & 0.0005 & 0.0275 \\
\hline 0.6 & 8344.5927 & 8344.5928 & 8344.594 & 0.0003 & 0.022 \\
\hline 0.7 & 8344.5927 & 8344.5928 & 8344.5934 & 0.0002 & 0.0259 \\
\hline 0.8 & 8344.5927 & 8344.5927 & 8344.5929 & 0.0001 & 0.0222 \\
\hline 0.9 & $\mathbf{8 3 4 4 . 5 9 2 7}$ & $\mathbf{8 3 4 4 . 5 9 2 7}$ & $\mathbf{8 3 4 4 . 5 9 2 8}$ & $\mathbf{0}$ & $\mathbf{0 . 0 1 7 5}$ \\
\hline
\end{tabular}

Table 2. Obtained Results for Emission Dispatch for System 1

\begin{tabular}{|c|c|l|l|l|l|}
\hline$p_{a}$ & $\begin{array}{c}\text { Min. } \\
\text { cost }(\$ / \mathrm{h})\end{array}$ & $\begin{array}{c}\text { Average } \\
\text { cost }(\$ / \mathrm{h})\end{array}$ & $\begin{array}{c}\text { Max. } \\
\operatorname{cost}(\$ / \mathrm{h})\end{array}$ & $\begin{array}{c}\text { Std. dev. } \\
(\$ / \mathrm{h})\end{array}$ & CPU time $(\mathrm{s})$ \\
\hline 0.1 & 0.09592393 & 0.0959 & 0.09593643 & 0 & 0.0276 \\
\hline 0.2 & 0.09592393 & 0.0959 & 0.09592761 & 0 & 0.0214 \\
\hline 0.3 & 0.09592393 & 0.0959 & 0.09592534 & 0 & 0.0291 \\
\hline 0.4 & 0.09592393 & 0.0959 & 0.09592438 & 0 & 0.0268 \\
\hline 0.5 & 0.09592393 & 0.0959 & 0.09592426 & 0 & 0.0222 \\
\hline 0.6 & 0.09592393 & 0.0959 & 0.09592407 & 0 & 0.0276 \\
\hline 0.7 & 0.09592393 & 0.0959 & 0.0959241 & 0 & 0.0237 \\
\hline 0.8 & 0.09592393 & 0.0959 & 0.09592398 & 0 & 0.0283 \\
\hline 0.9 & $\mathbf{0 . 0 9 5 9 2 3 9 3}$ & $\mathbf{0 . 0 9 5 9}$ & $\mathbf{0 . 0 9 5 9 2 3 9 4}$ & $\mathbf{0}$ & $\mathbf{0 . 0 2 2 1}$ \\
\hline
\end{tabular}


Table 3. Non-Dominated Solutions Obtained for System 1

\begin{tabular}{|c|c|c|c|c|}
\hline Solution & $\mathrm{w}_{1}$ & $\begin{array}{c}\text { Cost } \\
(\$ / \mathrm{h})\end{array}$ & $\begin{array}{c}\text { Emission } \\
(\mathrm{kg} / \mathrm{h})\end{array}$ & $\mu_{D}^{k}$ \\
\hline 1 & 1 & 8344.5927 & 0.0987 & 0.0499 \\
\hline 2 & 0.05 & 8344.5929 & 0.0987 & 0.0499 \\
\hline 3 & 0.007 & 8344.6020 & 0.0986 & 0.0517 \\
\hline 4 & 0.004 & 8344.6202 & 0.0985 & 0.0534 \\
\hline 5 & 0.003 & 8344.6393 & 0.0984 & 0.0552 \\
\hline 6 & 0.0017 & 8344.7232 & 0.0982 & 0.0585 \\
\hline 7 & 0.001 & 8344.9222 & 0.0980 & 0.0616 \\
\hline 8 & 0.0008 & 8345.0662 & 0.0978 & 0.0648 \\
\hline 9 & 0.0006 & 8345.3345 & 0.0976 & 0.0677 \\
\hline 10 & 0.0004 & 8345.9266 & 0.0974 & 0.0698 \\
\hline 11 & 0.0003 & 8346.5450 & 0.0971 & 0.0737 \\
\hline 12 & 0.0002 & 8347.7632 & 0.0968 & 0.0761 \\
\hline 13 & $\mathbf{0 . 0 0 0 1 2 5}$ & $\mathbf{8 3 4 9 . 7 2 0 3}$ & $\mathbf{0 . 0 9 6 5}$ & $\mathbf{0 . 0 7 6 7}$ \\
\hline 14 & 0.00007 & 8352.7861 & 0.0962 & 0.0746 \\
\hline 15 & 0.00003 & 8357.5460 & 0.0960 & 0.0665 \\
\hline 16 & 0 & 8365.1157 & 0.0959 & 0.0499 \\
\hline
\end{tabular}

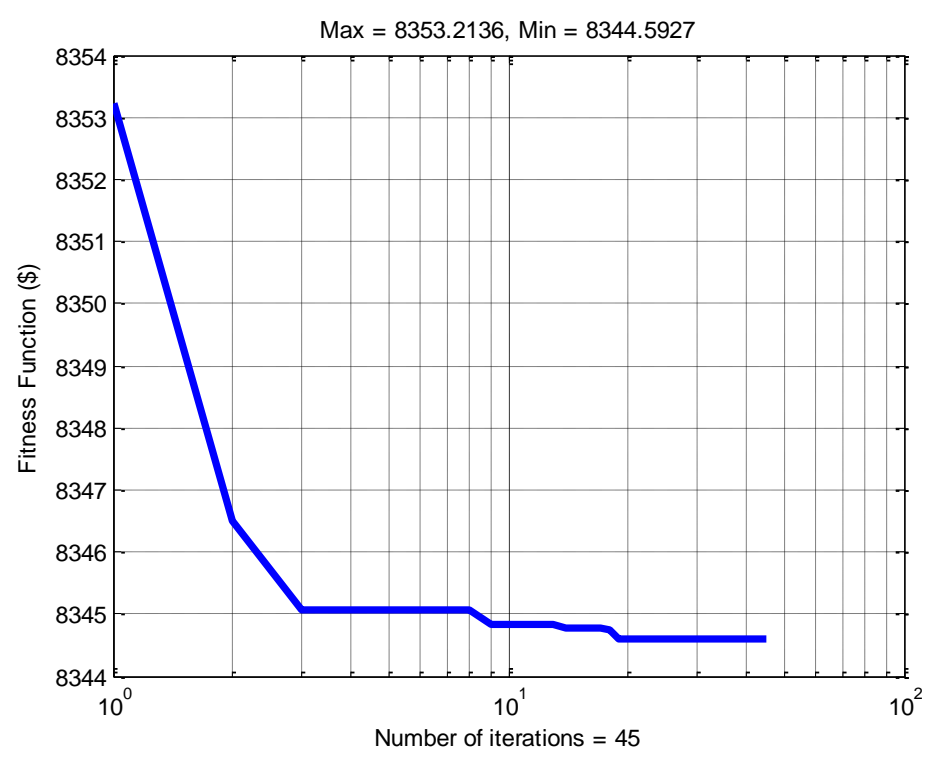

Figure 1. The Fitness Convergence Characteristic for Economic Dispatch 


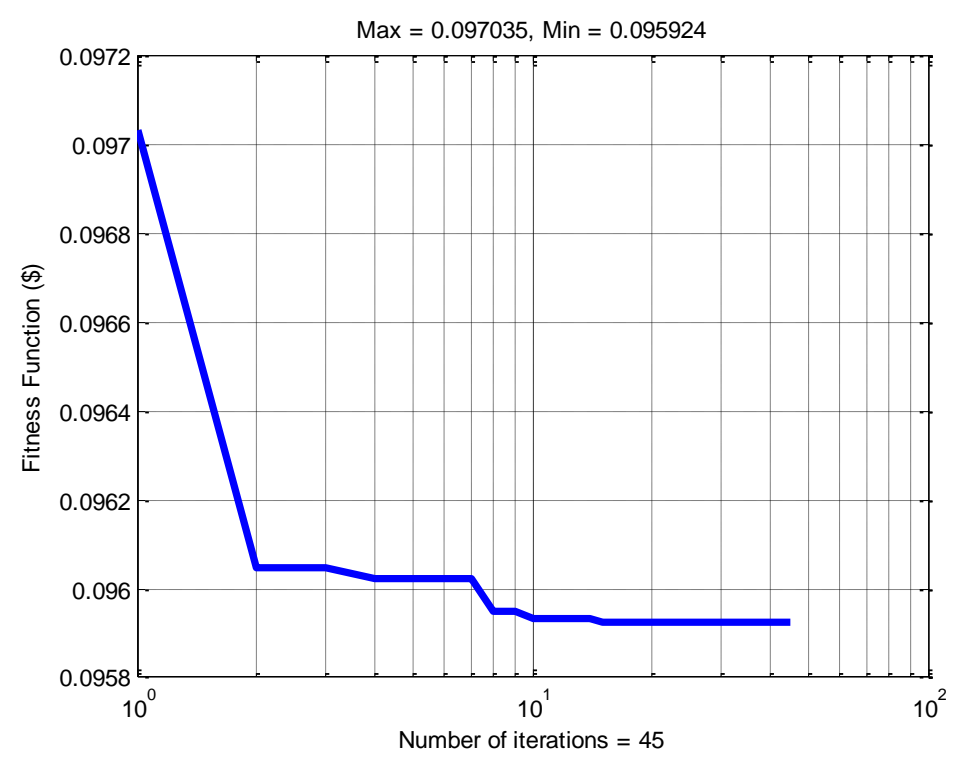

Figuere 2. The Fitness Convergence Characteristic for Remission Dispatch

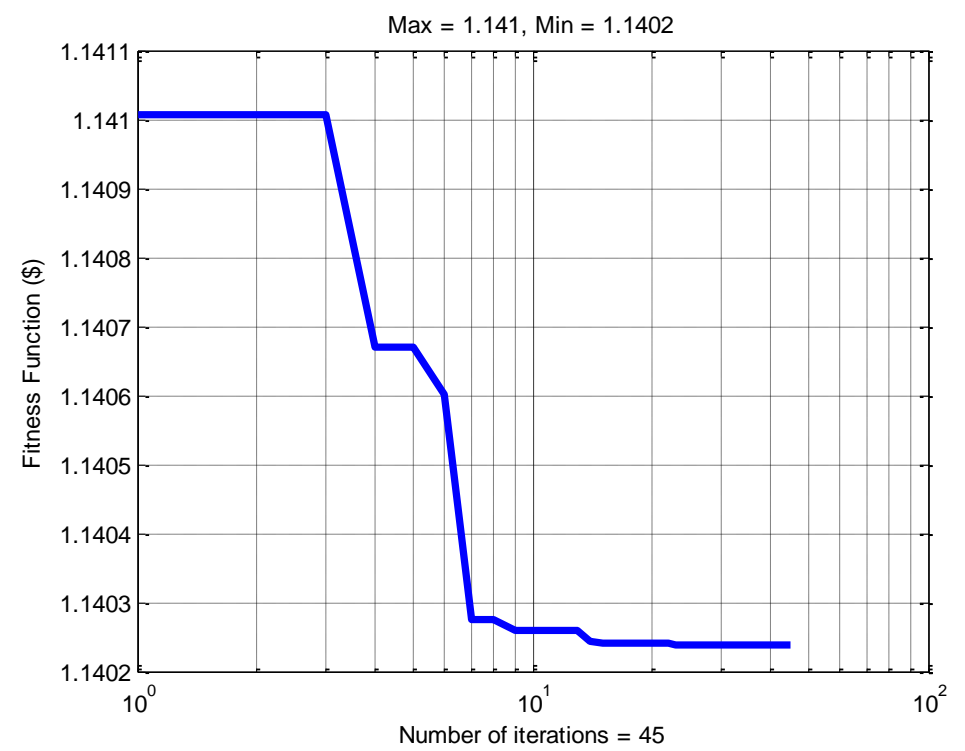

Figure 3. The Fitness Convergence Characteristic for Economic Dispatch 


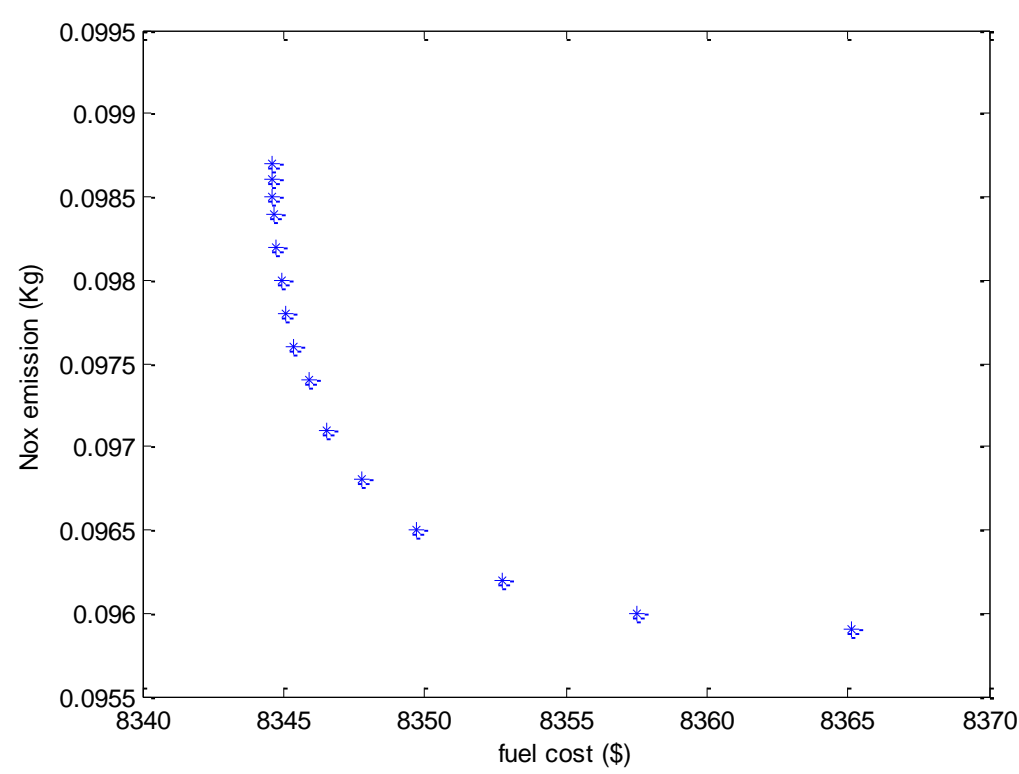

Figure 4. Pareto-Optimal Front for Fuel Cost and Emission for System I

Table 4. Result Comparisons for System 1

\begin{tabular}{|c|c|c|c|c|c|c|}
\hline Dispatch & Method & $\begin{array}{c}\text { Tabu Search } \\
\text { [3] }\end{array}$ & $\begin{array}{c}\text { NSGA-II } \\
\text { [5] }\end{array}$ & $\begin{array}{c}\text { BBO } \\
{[7]}\end{array}$ & CSA [11] & ORCSA \\
\hline \multirow{2}{*}{$\begin{array}{l}\text { Economic } \\
\text { dispatch }\end{array}$} & Cost $(\$ / h)$ & 8344.60 & 8344.60 & 8344.59 & 8344.59 & 8344.5927 \\
\hline & Cpu (s) & - & - & - & 0.09 & 0.0175 \\
\hline \multirow[t]{2}{*}{$\begin{array}{l}\text { Emission } \\
\text { dispatch }\end{array}$} & $\begin{array}{l}\text { Emission } \\
(\mathrm{kg} / \mathrm{h})\end{array}$ & 0.0958 & 0.09593 & 0.09592 & 0.09592 & 0.095924 \\
\hline & Cpu (s) & - & - & - & 0.07 & 0.0214 \\
\hline \multirow{3}{*}{$\begin{array}{l}\text { Economic } \\
\text { emission } \\
\text { dispatch }\end{array}$} & Cost $(\$ / h)$ & - & 8349.72 & & 8349.722 & 8349.7203 \\
\hline & $\begin{array}{l}\text { Emission } \\
(\mathrm{kg} / \mathrm{h})\end{array}$ & - & 0.09654 & & 0.09654 & 0.09654 \\
\hline & Cpu (s) & - & - & & 0.09 & 0.02 \\
\hline
\end{tabular}

Table 5. Optimal Generations for System 1

\begin{tabular}{|c|l|c|c|}
\hline $\begin{array}{c}\text { Generation } \\
(\mathrm{MW})\end{array}$ & $\begin{array}{c}\text { Economic } \\
\text { dispatch }\end{array}$ & $\begin{array}{c}\text { Emission } \\
\text { dispatch }\end{array}$ & $\begin{array}{c}\text { Economic } \\
\text { emission dispatch }\end{array}$ \\
\hline $\mathrm{P}_{1}$ & 435.1884 & 508.5316 & 470.8759 \\
\hline $\mathrm{P}_{2}$ & 299.9801 & 250.4805 & 280.8100 \\
\hline $\mathrm{P}_{3}$ & 130.6608 & 105.7343 & 113.6116 \\
\hline
\end{tabular}

\subsection{System II with Six Thermal Units}

Similar to the manners done in section 5.1 for system 1, optimal solutions obtained by the ORCSA for the three dispatch cases for three cases of load 800 MW, $1200 \mathrm{MW}$ and $1800 \mathrm{MW}$ are compared to those from other methods given in Tables 6, 7 and 8. Obviously, the ORCSA obtains better cost than CGA and FCGA in [4] for all cases, and approximate cost and emission with CSA [11] for all cases. 
On the other hand, OCSA is more robust than the CGA and FCGA because it spends much shorter time than these methods for searching optimal solutions. Although the ORCSA is slower than CSA for the load of $800 \mathrm{MW}$; however, it is faster than or as fast as CSA for rest of the cases. Consequently, it is concluded that the ORCSA is very efficient for solving the bi-objective load dispatch.

The optimal generations for the system are respectively given in Tables 9, 10 and 11 .

Table 6. Result Comparisons for System 2 for 800 MW Load

\begin{tabular}{|c|c|c|c|c|c|}
\hline Dispatch & Method & CGAs [4] & FCGAs [4] & CSA [11] & ORCSA \\
\hline \multirow{2}{*}{$\begin{array}{l}\text { Economic } \\
\text { dispatch }\end{array}$} & Cost $(\$ / h)$ & 8232.89 & 8231.03 & 8227.1 & 8227.1 \\
\hline & Cpu (s) & 14.46 & 5.62 & 0.031 & 0.139 \\
\hline \multirow[t]{2}{*}{$\begin{array}{l}\text { Emission } \\
\text { dispatch }\end{array}$} & $\begin{array}{l}\text { Emission } \\
(\mathrm{kg} / \mathrm{h})\end{array}$ & - & - & 526.3901 & 526.3902 \\
\hline & Cpu (s) & - & - & 0.03 & 0.14 \\
\hline \multirow{3}{*}{$\begin{array}{l}\text { Economic } \\
\text { emission } \\
\text { dispatch }\end{array}$} & Cost $(\$ / h)$ & - & - & 8269.5117 & 8333.1658 \\
\hline & $\begin{array}{l}\text { Emission } \\
(\mathrm{kg} / \mathrm{h})\end{array}$ & - & - & 568.8394 & 526.3902 \\
\hline & Cpu (s) & - & - & 0.032 & 0.14 \\
\hline
\end{tabular}

Table 7. Result Comparisons for System 2 for 1200 MW Load

\begin{tabular}{|c|c|c|c|c|c|}
\hline Dispatch & Method & CGAs [4] & FCGAs [4] & CSA [11] & ORCSA \\
\hline \multirow{2}{*}{$\begin{array}{l}\text { Economic } \\
\text { dispatch }\end{array}$} & Cost $(\$ / h)$ & 11493.74 & 11480.03 & 11477.09 & 11477.09 \\
\hline & Cpu (s) & 17.83 & 7.43 & 0.031 & 0.031 \\
\hline \multirow[t]{2}{*}{$\begin{array}{l}\text { Emission } \\
\text { dispatch }\end{array}$} & $\begin{array}{l}\text { Emission } \\
(\mathrm{kg} / \mathrm{h})\end{array}$ & - & - & 1113.3005 & 1113.3005 \\
\hline & Cpu (s) & & & 0.04 & 0.03 \\
\hline \multirow{3}{*}{$\begin{array}{l}\text { Economic } \\
\text { emission } \\
\text { dispatch }\end{array}$} & Cost $(\$ / h)$ & - & - & 11517.493 & 11517.4923 \\
\hline & $\begin{array}{l}\text { Emission } \\
(\mathrm{kg} / \mathrm{h})\end{array}$ & - & - & 1306.6945 & 1306.6952 \\
\hline & Cpu (s) & - & - & 0.032 & 0.031 \\
\hline
\end{tabular}

Table 8. Result Comparisons for System 2 for 1800 MW Load

\begin{tabular}{|c|c|c|c|c|c|}
\hline Dispatch & Method & CGAs [4] & FCGAs [4] & CSA [11] & ORCSA \\
\hline \multirow{2}{*}{$\begin{array}{l}\text { Economic } \\
\text { dispatch }\end{array}$} & Cost $(\$ / h)$ & 16589.05 & 16585.85 & 16579.33 & 16579.33 \\
\hline & Cpu (s) & 19.66 & 10.44 & 0.062 & 0.033 \\
\hline \multirow[t]{2}{*}{$\begin{array}{l}\text { Emission } \\
\text { dispatch }\end{array}$} & $\begin{array}{l}\text { Emission } \\
(\mathrm{kg} / \mathrm{h})\end{array}$ & - & - & 2511.9957 & 2511.9957 \\
\hline & $\mathrm{Cpu}(\mathrm{s})$ & - & - & 0.03 & 0.03 \\
\hline \multirow{3}{*}{$\begin{array}{l}\text { Economic } \\
\text { emission } \\
\text { dispatch }\end{array}$} & Cost $(\$ / h)$ & - & - & 16641.901 & 16641.9011 \\
\hline & $\begin{array}{l}\text { Emission } \\
(\mathrm{kg} / \mathrm{h})\end{array}$ & - & - & 2790.9434 & 2790.9442 \\
\hline & Cpu (s) & - & - & 0.034 & 0.035 \\
\hline
\end{tabular}


Table 9. Optimal Solution for Economic Dispatch for System 2

\begin{tabular}{|c|l|l|l|}
\hline $\begin{array}{c}\text { Generation } \\
(\mathrm{MW})\end{array}$ & \multicolumn{1}{|c|}{$\begin{array}{c}\mathrm{PD}=800 \\
(\mathrm{MW})\end{array}$} & $\begin{array}{c}\mathrm{PD}=1200 \\
(\mathrm{MW})\end{array}$ & \multicolumn{1}{|c|}{$\begin{array}{c}\mathrm{PD}=1800 \\
(\mathrm{MW})\end{array}$} \\
\hline $\mathrm{P}_{1}$ & 100.0000 & 123.6392 & 248.0000 \\
\hline $\mathrm{P}_{2}$ & 100.0000 & 117.7755 & 217.7194 \\
\hline $\mathrm{P}_{3}$ & 50.0000 & 50.0002 & 75.1815 \\
\hline $\mathrm{P}_{4}$ & 305.6282 & 448.4074 & 588.0396 \\
\hline $\mathrm{P}_{5}$ & 122.1880 & 230.1075 & 335.5304 \\
\hline $\mathrm{P}_{6}$ & 122.1838 & 230.0703 & 335.5292 \\
\hline
\end{tabular}

Table 10. Opimal Solution for Emission Dispatch for System 2

\begin{tabular}{|c|c|c|c|}
\hline $\begin{array}{c}\text { Generation } \\
(\mathrm{MW})\end{array}$ & $\begin{array}{c}\mathrm{PD}=800 \\
(\mathrm{MW})\end{array}$ & $\mathrm{PD}=1200(\mathrm{MW})$ & $\begin{array}{c}\mathrm{PD}=1800 \\
(\mathrm{MW})\end{array}$ \\
\hline $\mathrm{P}_{1}$ & 800.0000 & 1200.0000 & 1800.0000 \\
\hline $\mathrm{P}_{2}$ & 100.0000 & 176.4610 & 305.5857 \\
\hline $\mathrm{P}_{3}$ & 100.0000 & 176.4614 & 305.5841 \\
\hline $\mathrm{P}_{4}$ & 117.9446 & 172.1752 & 200.0000 \\
\hline $\mathrm{P}_{5}$ & 140.0000 & 172.1754 & 251.3893 \\
\hline $\mathrm{P}_{6}$ & 171.0149 & 251.3638 & 368.7223 \\
\hline
\end{tabular}

Table 11. Optimal Solution for Economic Emission Dispatch for System 2

\begin{tabular}{|c|c|c|c|}
\hline $\begin{array}{c}\text { Generation } \\
(\mathrm{MW})\end{array}$ & $\begin{array}{c}\mathrm{PD}=800 \\
(\mathrm{MW})\end{array}$ & $\mathrm{PD}=1200(\mathrm{MW})$ & $\begin{array}{c}\mathrm{PD}=1800 \\
(\mathrm{MW})\end{array}$ \\
\hline $\mathrm{P}_{1}$ & 800 & 1200 & 1800 \\
\hline $\mathrm{P}_{2}$ & 100 & 159.9966 & 283.4604 \\
\hline $\mathrm{P}_{3}$ & 100 & 151.4681 & 259.3105 \\
\hline $\mathrm{P}_{4}$ & 53.2197 & 76.8531 & 126.2103 \\
\hline $\mathrm{P}_{5}$ & 200.891 & 308.8486 & 412.8611 \\
\hline $\mathrm{P}_{6}$ & 172.946 & 251.4168 & 359.0789 \\
\hline
\end{tabular}

\section{Conclusion}

In this paper, a One Rank Cuckoo Search Algorithm has been successfully applied for solving bi-objective load dispatch problem. The ORCSA is an improved version of original CSA in which the first new solutions are newly generated directly before evaluating and ranking in addition to a bound by best solution technique for handling the inequality constraint. The performance of the ORCSA is validated by testing on two systems where large scale system with transmission line power losses is considered. The obtained result comparison have shown that the ORCSA is very efficient as applied to the bi-objective load dispatch because it can obtain better solution and faster simulation time than others. 


\section{References}

[1] N. T. Thang. 'Economic emission load dispatch with multiple fuel options using Hopfiled Lagrange Network'. International Journal of Advanced Science and Technology (2013), vol. 57, pp. 9-24.

[2] T. D. Kin, M. E. El-Hawary and F. El-Hawary, 'Optimal Environmental Dispatching of Electric Power Systems via an Improved Hopfield Neural Network Model', IEEE Trans. on Power Sysfems (1995), Vol. 10, pp. 1559-1565.

[3] C. A. Roa-Sepulveda, E. R. Salazar-Nova, E. Gracia-Caroca, U.G. Knight and A. Coonick. 'Environmental Economic Dispatch via Hopfield Neural Network and Taboo Search'. UPEC'96 Universities Power Engineering Conference, Crete, Greece, (1996), pp 1001-1004.

[4] Y. H. Song, G. S. Wang, P. Y. Wang and A. T. Johns. 'Environmental/econoimic dispatch using fuzzy logic controlled genetic algorithm'. IEE Proc-Gener. Transm. Distrib (1997), vol. 44 , pp 377-382

[5] C. S. Harry, Rughooputh and Robert T. F. A. King. 'Environmental/Economic Dispatch of Thermal Units using an Elitist Multiobjective Evolutionary Algorithm'. Industrial Technology, 2003 IEEE International Conference in Maribor, (2003), Slovenia 1, pp 48-53.

[6] K. K. Mandal and N. Chakraborty, 'Effect of Control Parameters on Differential Evolution based Combined Economic Emission Dispatch with Valve-Point Loading and Transmission Loss'. International Journal of Emerging Electric Power Systems (2008), vol. 9, pp 1-18.

[7] P. K. Roy, S. P. Ghoshal and S. S. Thakur, 'Combined economic and emission dispatch problems using biogeography-based optimization'. Electr Eng (2010), vol.92, pp. 173-184.

[8] M. Basu, 'Economic environmental dispatch using multi-objective differential evolution', Applied Soft Computing (2011), vol. 11, pp. 2845-2853.

[9] A.M. Elaiwa, X. Xiab and A.M. Shehata, 'Hybrid DE-SQP and hybrid PSO-SQP methods for solving dynamic economic emission dispatch problem with valve-point effects'. Electric Power Systems Research (2013), vol. 103, pp. 192-200.

[10] H. Hamedi, 'Solving the combined economic load and emission dispatch problems using new heuristic algorithm'. Electrical Power and Energy Systems (2013), vol. 46, pp. 10-16.

[11] N. T. P. Thao and N. T. Thang, 'Environmental Economic Load Dispatch with Quadratic Fuel Cost Function Using Cuckoo Search Algorithm'. International Journal of u- and e- Service, Science and Technology (2014), Vol.7, No.2, pp.199-210.

[12] S.T. Ahmed, A.B Amr, F.A. Ibrahim, One Rank Cuckoo Search Algorithm with Application to Algorithmic Trading Systems Optimization, International Journal of Computer Applications 64 (2013) 30-37.

[13] A. George, M. C. Reddy and A. Y. Sivaramakrishnan, 'Multi-objective, short-term hydro thermal scheduling based on two novel search techniques', International Journal of Engineering Science and Technology (2010), Vol. 2, No. 11, pp. 7021-7034 .

[14] M. Sakawa, H. Yano and T. Yumine, 'An interactive fuzzy satisfying method for multi-objective linear programming problems and its applications'. IEEE Trans. Systems, Man, and Cybernetics (1987), vol.17, No. 4, pp. 654-661.

\section{Authors}
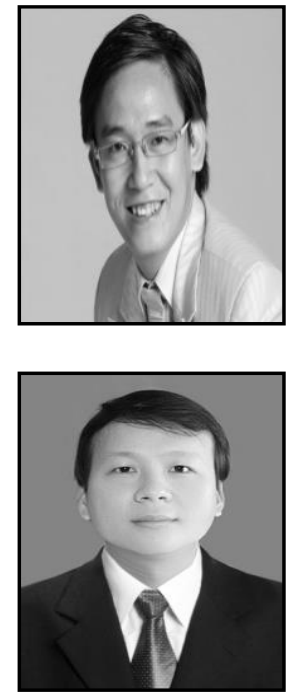

Cuong Dinh Tran. He has graduated from the university of technology Ho Chi Minh city, Ho Chi Minh city, VietNam. He received her B.Eng and M.Eng degrees in Electrical Engineering in 2005 and 2008, respectively. Now, he is teaching at department of electrical engineering, Ton Duc Thang university, Ho Chi Minh city, Vietnam. His research interests include intelligent control system, power system operation and control, and Renewable Energy.

Thang Trung Nguyen. He received his B.Eng. and M.Eng degrees in Electrical Engineering from University of Technical education Ho Chi Minh City, Ho Chi Minh city, Vietnam in 2008 and 2010, respectively. Now, he is teaching at department of electrical and electronics engineering, Ton Duc Thang university, Ho Chi Minh city, Vietnam. His research interests include optimization of power system, power system operation and control and Renewable Energy. 

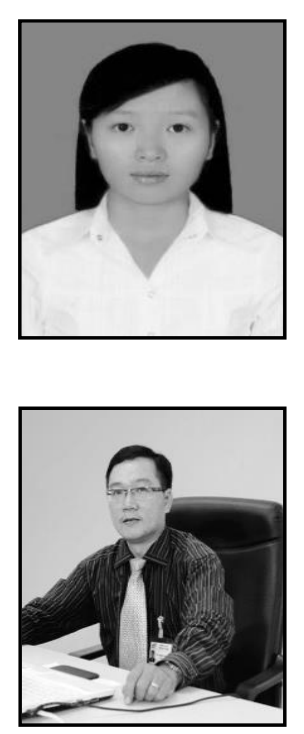

Hanh Hoang Minh. She received her B. Engineer degree in in Electrical Engineering from University of Technical education Ho Chi Minh City, Ho Chi Minh city, Vietnam in 2008, and M.Eng from Ho Chi Minh city University of Transport in 2010. Now she is teaching at Faculty of Automations, Thu Duc College of Technology, Ho Chi Minh city, Vietnam. Her research interests include optimization of power system, optimal control of motor.

Bao Quoc Nguyen. He received B.Eng and M.Eng degrees from the university of technology Ho Chi Minh city in 1995 and 1998. Now, he is a PhD student at department of electrical and electronics engineering, Ton Duc Thang university, Ho Chi Minh city, Vietnam. His research interests include power system optimization, optimal power flow and control of motor. 